\title{
Carrot (Daucus carota) - Ultimate Source of Nutrition: An Appraisal
}

\author{
Versha $^{1}$, D.S. Bunkar ${ }^{1}$ and S. K. Goyal ${ }^{2 *}$ \\ ${ }^{1}$ Centre of Food Science and Technology, Institute of Agricultural Sciences, Banaras Hindi \\ University, Varanasi (U.P.) \\ ${ }^{2}$ BHU-KVK, Institute of Agricultural Sciences, RGSC, Banaras Hindi University, Barkachha, \\ Mirzapur (U.P.) \\ *Email: sunil.svbp@gmail.com
}

\begin{abstract}
Carrots are one of the most widely used and enjoyed vegetables in the world, because it grow relatively easily and are very versatile in a number of dishes and cultural cuisines. Carrots are scientifically classified as Daucus carota and it is categorized as a root vegetable. It is typically red or orange in color, but purple, white, yellow, and black carrots are not as common. The taproot of the carrot is the part of the vegetable most commonly eaten, although the greens are still beneficial in salads and other forms. The type of carrot most commonly eaten around the world is the domesticated variation of the wild species and it is native to Europe and south western Asia. The majority of carrots are now cultivated in China, but they are exported throughout the world to be included in salads and soups, as well as a stand-alone vegetable for snacks, side dishes, and essential ingredients in many recipes. As an important source of carotene, carrot is widely recommended by physicians for innumerable medicinal purposes. These small eatables are a goldmine of nutrients and contain Vitamin A, B and C as well as calcium pectate. Its pectin fibre is beneficial in lowering the cholesterol level of the body. Carrot is a root vegetable with carotenoids, flavonoids, polyacetylenes, vitamins, and minerals, all of which possess numerous nutritional and health benefits. Besides lending truth to the old adage that carrots are good for eyes, carotenoids, polyphenols and vitamins present in carrot act as antioxidants, anticarcinogens, and immunoenhancers. Anti-diabetic, cholesterol and cardiovascular disease lowering, anti-hypertensive, hepatoprotective, renoprotective, and wound healing benefits of carrot have also been reported. The cardio and hepatoprotective, anti-bacterial, anti-fungal, antiinflammatory, and analgesic effects of carrot seed extracts are also noteworthy. All the nutritional and health benefits are discussed in this paper.
\end{abstract}

Keywords: Carrot, carotene, nutrition, phenolic compounds, ultimate source.

Paper cited: Versha; Bunkar, D.S. and Goyal, S.K. (2019). Carrot (Daucus carota) - Ultimate Source of Nutrition: An Appraisal. South Asian Journal of Food Technology and Environment, 5(1): 753762.

\section{Introduction}

The carrot (Daucus carota sub sp. sativus) is a root vegetable usually red or orange in colour, though purple, black, white, and yellow varieties exist. The most commonly eaten part of a carrot is a taproot, although the greens are sometimes eaten as well. It is a domesticated form of the wild carrot Daucus carota, native to Europe and south western Asia. The domestic carrot has been selectively bred for its greatly enlarged and more palatable, less woody-textured edible taproot (Kalra et al., 1987).

Carrots are grown from seed and can take up to 120 days to mature, but many varieties mature in 70 to 80 days under the right and favourable conditions. They grow best in full sun but tolerate some shade. The optimum temperature is 16 to $21{ }^{\circ} \mathrm{C}$. The ideal soil is deep, loose and well-drained, sandy or loamy, with a pH of 6.3 to 6.8 . Fertilizers should be applied according to soil type because the crop requires low levels of nitrogen, moderate phosphate and high potash. Rich or rocky soils 
should be avoided, as these will cause the roots to become hairy and/or misshapen (Rubatzky et al., 1999). Irrigation is applied when needed to keep the soil moist. After sprouting, the crop is eventually thinned to a spacing of 8 to $10 \mathrm{~cm}$ and weeded to prevent competition beneath the soil (CSIR, 2010). It is basically a root vegetable having pinnately decompound leaves and umbels of small white or yellow flowers. The edible portion of a carrot is its taproot, eaten raw or cooked (Simon and Wolff, 1987).

Although carrots are available throughout the year, locally grown carrots are in season in the summer and fall when they are the freshest and most flavorful. Carrots belong to the Umbelliferae family, named after the umbrella-like flower clusters that plants in this family produce (CSIR, 2010). As such, carrots are related to parsnips, fennel, parsley, anise, caraway, cumin and dill. Carrots can be as small as two inches or as long as three feet, ranging in diameter from one-half of an inch to over two inches (Gill and Kataria, 1974). Carrot roots have a crunchy texture and a sweet and minty aromatic taste, while the greens are fresh tasting and slightly bitter. While we usually associate carrots with the color red and orange, carrots can actually be found in a host of other colors including white, yellow, purple or black. In fact, purple, yellow and red carrots were the only color varieties of carrots to be cultivated before the 15th or 16th century (Grassmann et al., 2007).

\section{Characteristics}

The carrot gets its characteristic, bright red or orange colour from $\beta$-carotene, and lesser amounts of $\alpha$-carotene, $\gamma$-carotene, lutein and zeaxanthin. $\alpha_{-}$and $\beta$-carotenes are partly metabolized into vitamin A, providing more than $100 \%$ of the Daily Value (DV) per $100 \mathrm{~g}$ serving of carrots (Simon and Wolff, 1987). Carrots are also a good source of vitamin $\mathrm{K}(13 \% \quad \mathrm{DV})$ and vitamin B6 (11\% DV) (Krinsky, 1989), but otherwise have modest content of other essential nutrients (Algarra et al., 2014). Carrot dietary fiber comprises mostly cellulose, with smaller proportions of hemi-cellulose, lignin and starch (DavidsonHunt, 2006). Free sugars in carrot include sucrose, glucose and fructose (Fu et al., 2009). Carrots can be stored for several months in the refrigerator or over winter in a moist and cool place. For long term storage, unwashed carrots can be placed in a bucket between layers of sand, a 50/50 mix of sand and wood shavings, or in soil. A temperature range of 0 to $5{ }^{\circ} \mathrm{C}$ is best (CSIR, 2010). Carrots in the wild have a woody core element that is not very palatable, so cultivation has eventually selected that characteristic out so we are left with the form of carrots that we are familiar with today. Both adults and children like carrots because of their crunchy texture and sweet taste, so this is one of the valuable vegetables for parents as well as children (Byers and Perry, 1992).

Even though consumers are most familiar with carrots as root vegetables bright orange in color, an amazing variety of colors are found worldwide for this vegetable. All of these color varieties, however, still belong to the same genus and species of plant, Daucus carota (Simon and Wolff, 1987; Kalra et al., 1987).

\section{Classification of carrots based on colour}

Here is a short list of some of the more popular carrot varieties, (Leja et al., 2013) categorized by color:

- Red Carrots

Supreme Chateney

$>$ Red Samurai

- Orange Carrots

Scarlet Nantes (especially valued for its sweetness)

$>$ Danvers (often raised for processing)

$>$ Camden (often raised for processing)

$>$ Other popular varieties include Navajo, Sirkana, Top Cut and Inca

- Purples Carrots

$>$ Indigo

$>$ Maroon

> Purple Dragon

$>$ Cosmic Purple

$>$ Purple Haze

- Yellow Carrots

$>$ Sunlite

$>$ Solar Yellow

$>$ Yellowstone

- White Carrots

$>$ Creme De Lite

$>$ White Satin

The carrot can trace its ancestry back thousands of years, originally having been 
cultivated in central Asian and Middle Eastern countries, along with parts of Europe. These original carrots looked different from those that we are accustomed to today, featuring red, purple, and yellow coloring rather than the bright orange that we've become accustomed to in supermarkets and malls. Carrots became widely cultivated in Europe during the 15th and 16 th centuries and were first brought over to North America during this same general time period (CSIR, 2010).

In today's commercial marketplace, China currently produces about one-third of all carrots bought and sold worldwide. Russia is the second largest carrot producer, with the U.S. following a close third. Many European countries produce substantial amounts of carrots (over 400,000 metric tons) and Turkey, Mexico, India, Indonesia, Australia and Canada are also important countries in the worldwide production of carrots. Within the U.S., about 12,000 acres of carrots for processing are planted each year, resulting in about 320,000 tons of carrots. Over $80 \%$ of all fresh market carrot production in the U.S. comes from California, with Michigan and Texas emerging as the next two largest fresh production states (Verma et al., 2014).

\section{Phenolic compound}

Phenolic compounds are found in most fruits and vegetables (Zhang and Hamauzu, 2005). Carrots and their fresh produce (shredded carrots, sliced carrots and carrot juice) may protect humans against certain types of cancer and cardiovascular diseases (Krinsky, 1989). Carrots contain mainly hydroxycinnamic acids and derivatives. Among them, chlorogenic acid is a major hydroxycinnamic acid, representing from $42.2 \%$ to $61.8 \%$ of total phenolic compounds (Kahkonen et al., 1999). In addition to the above mentioned compounds found in natural foods, vitamins $\mathrm{C}$ and $\mathrm{E}$, betacarotene and tocopherol are known to possess antioxidant potential (Karakaya et al., 2001). The presence of phenolic compounds in carrots contributes to their sensory qualities, like colour (Zhang and Hamauzu, 2005), bitterness (Grassmann et al., 2007), or aroma (Sun et al., 2009). Therefore, the response of phenolic compounds could be used as a good indicator to evaluate the carrots quality during processing and storage. The quality of carrots mostly depends on the components accumulated in fresh matrix, peel and cortex (Mayer and Spie, 2003). Therefore it is very important to precisely estimate the quality of carrots. There were determined relative levels of antioxidant activity in several of carrots consisting of a variety of vegetable families, selected on the basis of their widespread use in traditional consumption via scavenging of 2,2-diphenyl-2picryl hydrazyl hydrate (DPPH) radical determined spectrophotometrically. A number of carrot species with appreciable levels of antioxidant activity against the DPPH radical were identified as potential sources of free radical scavenging compounds (Simon and Wolff, 1987). Carrots are good sources of natural antioxidants containing many different antioxidant components. These antioxidants include carotenoids, vitamins, phenolic compounds, flavonoids, dietary glutathione and endogenous metabolites and have been shown to function as singlet and triplet oxygen quenchers, free radical scavengers, peroxide decomposers, enzyme inhibitors, and synergists (Shakuntalamanay and Shadaksharaswamy, 1997).

\section{Health Benefits}

The name "carrot" comes from the Greek word "karoton," whose first three letters (kar) are used to designate anything with a horn-like shape. (That horn-like shape, of course, refers to the taproot of the carrot that is the plant part we are most accustomed to consuming). The beta-carotene that is found in carrots was actually named for the carrot itself (Mittal et al., 2011). The health benefits of carrots include reduced cholesterol, prevention from heart attacks, warding off of certain cancers, improving vision, and reducing the signs of premature aging. Furthermore, carrots have the ability to increase the health of your skin, boost the immune system, improve digestion, increase cardiovascular health, detoxify the body, and boost oral health in a variety of ways. It also provides a well-rounded influx of vitamins and minerals (Gilani et al., 1994).

Carrots are perhaps best known for their rich supply of the antioxidant nutrient that was actually named for them: beta-carotene. However, these delicious root vegetables are the source not only of beta-carotene, but also of 
a wide variety of antioxidants and other healthsupporting nutrients (Vasudevan and Parle, 2006). The areas of antioxidant benefits, cardiovascular benefits, and anti-cancer benefits are the best-researched areas of health research with respect to dietary intake of carrots (Shukla et al., 2014).

Antioxidant Benefits: All varieties of carrots contain valuable amounts of antioxidant nutrients. Included here are traditional antioxidants like vitamin $\mathrm{C}$, as well as phytonutrient antioxidants like beta-carotene. The list of carrot phytonutrient antioxidants is by no means limited to beta-carotene, however, this list includes (Sivanatham and Thangaraj, 2015):

- Carotenoids

- alpha-carotene

- beta-carotene

- lutein

- Hydroxycinnamic acids

- caffeic acid

- coumaric acid

- ferulic acid

- Anthocyanindins

- cyanidins

- malvidins

Different varieties of carrots contain differing amounts of these antioxidant phytonutrients. Red and purple carrots are best known for the rich anthocyanin content. Orange carrots are particularly outstanding in terms of beta-carotene, which accounts for $65 \%$ of their total carotenoid content. In yellow carrots, $50 \%$ of the total carotenoids come from lutein (Poudyal et al., 2010).

Cardiovascular Benefits: It is not surprising to find numerous research studies documenting the cardiovascular benefits of carrots due to their antioxidant richness. Our cardiovascular system needs constant protection from antioxidant damage. This is particularly true of our arteries, which are responsible for carrying highly oxygenated blood (Bast and Haenen, 1996). Antioxidant nutrients in carrots are believed to explain many of the cardioprotective benefits provided by these root vegetables (Muralidharan et al., 2008). Many different kinds of carrot antioxidants are most likely to work together and provide us with cardiovascular benefits that we could not obtain from any of these antioxidants alone if they were split apart and consumed individually, in isolation from each other. The synergistic effect of carrot antioxidants is a great example of a whole food and its uniqueness as a source of nourishment (Bendich, 1994).

Yet in addition to the diverse mixture of carrot antioxidants, there is yet another category of carrot phytonutrient that is believed to help explain carrot protection against cardiovascular disease. That category is polyacetylenes. Polyacetylenes are unique phytonutrients made from metabolism of particular fatty acids (often involving crepenynic acid, stearolic acid and tariric acid (Grassmann et al., 2007). They are particularly common in the plants of Apiaceae /Umbelliferae family of which includes carrot. The two best-researched polyacetylenes found in carrot are falcarinol and falcarindiol (Heinonen, 1990). Preliminary research on animals and in the lab has shown that carrot polyacetylenes have anti-inflammatory properties and anti-aggregatory properties. That help to prevent excessive clumping together of red blood cells. So in addition to the unique mix of antioxidants in carrot, polyacetylenes may play a key role in the cardiovascular protection provided by this amazing food (Bendich and Olson, 1989).

Vision Health: Carrots are rich in betacarotene which is converted into vitamin A in the liver (Grassmann et al., 2007). Vitamin A is transformed in the retina, to rhodopsin, a purple pigment necessary for night vision. Betacarotene has also been shown to protect against macular degeneration and senile cataracts. A study found that people who eat large amounts of beta-carotene had a 40 percent lower risk of macular degeneration than those who consumed little (Bast and Haenen, 1998).

Anti-Cancer Benefits: The anti-cancer benefits of carrot have been best researched in the area of colon cancer. Some of this research has involved actual intake of carrot juice by human participants, and other research has involved the study of human cancer cells types in the lab (Poudyal, 2010). Lab studies have shown the ability of carrot extracts to inhibit the grown of colon cancer cells, and the polyacetylenes found in carrot (especially falcarinol) have been specifically linked to this inhibitory effect. In studies of carrot juice intake, small but significant effects on colon cell health have been shown for participants 
who consumed about 1.5 cups of fresh carrot juice per day (Patil et al., 2012). Carrots are simply too rich in digestive tract-supporting fiber, antioxidant nutrients, and unique phytonutrients like falcarinol to be neutral when it comes to support of the lower digestive tract and colon cancer protection.

Slows down aging: The high level of beta-carotene in carrots acts as an antioxidant to cell damage done on the body through regular metabolism. It help slows down the aging of cells (Khalil et al., 2015).

Protects teeth and gums: Due to crunchiness of carrots, they clean your teeth and mouth and scrape off plaque and food particles just like toothbrushes or toothpaste. Carrots stimulate gums and trigger a lot of saliva, which, being alkaline, balances out the acidforming, cavity-forming bacteria. The minerals in carrots also prevent tooth damage (Ksouri et al., 2015).

Cleanses the body: Vitamin A assists the liver in flushing out the toxins from the body. It reduces the bile and fat in the liver. The fiber present in carrots helps clean out the colon and hasten waste movement (El-Houri et al., 2015).

Helps prevent infection: Carrots are known by herbalists to prevent infection. They can be used on cuts shredded raw or boiled and mashed (El-Moghazi, 1980).

\section{$\boldsymbol{\beta}$-Carotene - a main source of vitamin A and $B$ complex}

$\beta$-Carotene is an organic, strongly colored red-orange pigment abundant in plants and fruits. It is a member of the carotenes, which are terpenoids (isoprenoids), synthesized biochemically from eight isoprene units and thus having 40 carbons. Among the carotenes, $\beta$-carotene is distinguished by having betarings at both ends of the molecule (Bast and Haenen, 1996). $\beta$-Carotene is biosynthesized from geranylgeranyl pyrophosphate. $\beta$-Carotene is the most common form of carotene in plants. When used as a food coloring, it has the $\mathrm{E}$ number e.g. E160a. In nature, $\beta$-carotene is a precursor (inactive form) to vitamin A via the action of beta-carotene 15,15'-monooxygenase (Poudyal, 2010).

Isolation of $\beta$-carotene from fruits abundant in carotenoids is commonly done using column chromatography. It can also be extracted from the beta-carotene rich algae, Dunaliella Salina. The separation of $\beta$ carotene from the mixture of other carotenoids is based on the polarity of a compound. $\beta$ Carotene is a non-polar compound, so it is separated with a non-polar solvent such as hexane. Being highly conjugated, it is deeply colored, and as a hydrocarbon lacking functional groups, it is very lipophilic. Betacarotene is found in many foods and is sold as a dietary supplement. Medical authorities generally recommend getting beta-carotene from food rather than supplementation (Bast and Haenen, 1998).

Plant carotenoids are the primary dietary source of provitamin A worldwide, with $\beta$-carotene as the most wellknown provitamin A carotenoid (Hedren et al., 2002). Others include $\alpha$-carotene and $\beta$ cryptoxanthin. Carotenoid absorption is restricted to the duodenum of the small intestine and dependent on Class B scavenger receptor (SR-B1) membrane protein, which are also responsible for the absorption of vitamin E ( $\alpha$-tocopherol) (Bendich, 1994). One molecule of $\beta$-carotene can be cleaved by the intestinal enzyme $\beta, \quad \beta$-carotene 15,15'monooxygenase into two molecules of vitamin A. Absorption efficiency is estimated to be between 9-22\%. The absorption and conversion of carotenoids may depend on the form that the $\beta$-carotene is in (e.g., cooked vs. raw vegetables, or in a supplement) (Panalanks and Murray, 1970), the intake of fats and oils at the same time, and the current stores of vitamin A and $\beta$-carotene in the body (Edwards and Lee, 1986).

\section{Value added products from Carrot}

There are many carrot products are available in the indian and other food markets like, carrot juices, carrot soups, carrot halwa, carrot pickle, carrot mix pickle, carrot jam, carrot kher, carrot ice cream, carrot candy, food supllements, carrot powder, grits, etc.

Carrot juice: Carrot juice has a particularly high content of $\beta$-carotene, a source of vitamin A, but it is also high in B complex vitamins like folate, and many minerals including calcium, copper, magnesium, potassium, phosphorus and iron (Sinchaipanit and Kerr, 2007). A pound (454 g) of carrots will yield about a cup of juice (about 
$236 \mathrm{ml}$ ), which is a low yield compared to fruits like apples and oranges. However, carrot pulp is very tough; the main difficulty in juicing carrots is in separating the pulp from the juice (Karangwa et al., 2010).

Carrot Soup: Carrot soup is a soup prepared with carrot as a primary ingredient. It may be prepared as a cream or broth-style soup. Additional vegetables, root vegetables and various other ingredients may be used in its preparation. It may be served hot or cold. There are several recipes exist in the world food market (Czepa and Hofmann, 2003). Carrot soup has been described as a "classic" dish in French cuisine. Other vegetables may be used in the dish, including root vegetables, the latter of which may include garlic, onion, potato, turnip and others. Carrot juice and orange juice may be used in its preparation, and some versions are prepared using puréed carrot (Sharma et al., 2009).

After cooking, the dish may be run through a sieve to strain it. The carrots used may be peeled or unpeeled, and the use of peeled carrots can lend to increased smoothness in puréed versions of the dish. Those prepared with puréed carrot may have a thick consistency while also being smooth in texture. The soup's color can vary based upon the coloration of the carrots used. Young carrots tend to make the soup sweeter and imbue it with a bright orange coloration, while older, larger carrots provide less sweetness and may imbue a yellow coloration. The use of old, cracked carrots that have a woody texture in their interior can produce a soup of inferior quality (Bao and Chang, 1994).

Several ingredient variations exist in carrot soup preparations. Some carrot soups are prepared using coconut milk, coconut water, coconut cream, coconut butter or coconut pieces. Some versions include ginger as an ingredient, and some include curry (Banga and Bawa, 2002). Green carrot leaves (greens) from the top of carrots may be used as an ingredient in the dish. Chopped mint leaves are used in some versions. It may be served hot or chilled. Salt and pepper may be used to season the dish, and nutmeg is sometimes used as a seasoning. It is sometimes topped with yogurt, a yogurt sauce, crème fraîche, sour cream, and other ingredients (Ambadan, 1971). $\begin{array}{crcc}\text { Like } & \text { many } & \text { products high in beta- } \\ \text { carotene, } & \text { it } & \text { may } & \text { cause }\end{array}$ temporary carotenoderma, a benign skin condition resulting in an orange-yellow hue to the skin (Simon and Linday, 1983). Drinking more than 3 cups of carrot juice in a 24-hour period, over a prolonged period of time may be enough to cause this condition (Karangwa et al., 2010). Carrot juice has a uniquely sweet flavour of concentrated carrots. Unlike many juices, it is opaque. It is often consumed as a health drink. Carrots have been made into soups and juices for hundreds of years. Earlier in food industry carrot juice was one of the first colorants used to make cheese a darker color (Bawa and Saini, 1987).

Carrot Preserve: Carrot preserve is prepared by boiling the carrot slices in sugar syrup until the total soluble solids of the product reaches 55-70\% (Cruess, 1997). Preserve is an intermediate moisture food and involves osmotic concentration. Carrot preserve has been made by pretreating the boiled carrots with $40^{\circ}$ Brix for $12 \mathrm{hrs}$, followed by dipping in $60^{\circ}$ Brix for the same time and finally in the $70^{\circ}$ Brix concentrations with sample to syrup ratio as 1:4 (Singh et al., 1999) whereas, a solution of sugar, water, glycol, acid and preservative was used for the preparation of intermediate moisture carrot slices.

Carrot jam: Jam is a product made from pulp and boiling it with the required quantity of sugar in presence of pectin at a low $\mathrm{pH}$ until the formation of gel like fruits but can be extended to some vegetables like carrot, tomato, cucumber, pumpkin and sweet potato (Gopalan et al., 1991). The most common method of jam making involves heat treatment in boiling water to carrot slices for about 30 min to soften the slices (Roy et al., 2017). The development of puree by homogenizing the slices in food processor for couple of minutes follows with the addition of required quantity of sugar and cooking for about 15 min to a gel like consistency. The mild method uses lemon juice and pectin as additional ingredients required for the proper gelation of the product. The washed carrots are processed through a juicer to obtain juice and pomace that are subsequently mixed together with addition of citrus juice to prevent carotene oxidation. The mixture is cooked with sucrose and finally added with pectin to the gel consistency. The mild method of production is 
preferable as it retains more phenolics, carotene, color and potassium than the common method of jam production from commercial, purple, orange and yellow colored roots (Roy et al., 2017). The juice from the black carrot has been used as for the enhancement of color for strawberry jams as reported by Kirca et al., (2007).

Other value added products from carrot: The quality is the limiting parameter for the utilization of carrots as "carrot sticks" widely used in restaurants. The shelf life of the sticks gradually decreases to 2 weeks from 4 to 6 weeks; the latter is the case with fresh carrots. Rokheri et al., (2013) demonstrated the synergestic use of antimicrobials, antioxidants, cellular components and vacuum packaging in enhancing the storage period of the carrot sticks.

Gazrella or sweet meat is a carrot based sweet Indian product made from carrot shreds and condensed milk along with cane sugar and moderately frying in hydrogenated oil (Singh, 2001). Jayaraman and Gupta (1978) observed that gazrella prepared from carrot shreds treated with $35 \mathrm{~g}$ sucrose per $100 \mathrm{~g}$ shreds followed by drying has highest sensory quality. Honey based carrot candy was developed by Madan and Dhawan (2005) and Durrani et al., (2011). Carrot powder and grits based food supplements were also prepared by researchers.

Carrot halwa (gajarkahalwa) is a sweet dish very popular in the northern India and is prepared by cooking shredded carrots in hydrogenated oil along with sugar, milk powder and dry fruits (Sampathu et al., 1981). Negi and Roy (2001) developed carrot dessert mix from dehydrated blanched carrots with the addition of powdered sugar, milk powder, coconut powder and dry fruits. The mix is available commercially by the brand name of "Kanwal Carrot Dessert" and prepared by mixing with three times water to fully rehydrate the product following by addition of clarified butter. Suman and Krishnakumari (2002) utilized the dehydrated carrot shreds and powder for the preparation of curry, halwa and biscuits. Carrot kheer mix and Carrot milk cake developed by Manjunatha et al., (2003) and Gupta et al., (2005), respectively.

\section{Conclusion}

Carrot has remarkable nutritional and health benefits. There are good reasons to include carrots in human diet, since they are enriched with carotenoids, phenolic compounds, polyacetylenes, and vitamins and by this reason they may help reduce the risk of some diseases. Experimental evidence has reported that these carrot compounds exert antioxidative, anticarcinogenic, and immunoenhancer effects. Anti-diabetic, cholesterol and cardiovascular disease lowering, anti-hypertensive, hepatoprotective, renoprotective, and wound healing benefits of carrot have also been reported. The mechanism by which these carrot compounds decrease the risk of some diseases is complex and sometimes largely unknown

\section{References}

Algarra, M., Fernandes, A., Mateus, N. and Casado, J. (2014). Anthocyanin profile and antioxidant capacity of black carrots (Daucus carota L. spp. Sativus var. atrorubens Af.)) from Cuevas Bajas, Spain. Journal of Food Composition and Analysis, 33: 71-76.

Ambadan, J.N. (1971). New blanching medium for dehydration of carrot. Indian Food Packer, 25(4): 10-13.

Banga, R. and Bawa, A.S. (2002). Studies on dehydration of grated carrots. Journal of Food Science and Technology, 39(3): 268-271.

Bao, B. and Chang, K. C. (1994). Carrot pulp chemical composition, color, and water holding capacity as affected by blanching. Journal of Food Science, 59(6): 1159-1161.

Bast, A. and Haenen, G.R. (1996). Betacarotene as antioxidant. European Journal of Clinical Nutrition, 50(5): 46.

Bast, A. and Haenen, G.R. (1998). Antioxidant effects of carotenoids. International Journal for Vitamin and Nutrition Research, 68(6): 399-403.

Bawa, A.S. and Saini, S.P.S. (1987). Effect of method of preservation on the storage quality of carrot juice. Indian Food Packer, 41(1): 42-46. 
Bendich, A. and Olson, J. A. (1989). Biological actions of carotenoids. The FASEB Journal, 3(8): 1927-1932.

Bendich, A. (1994). Recent advances in clinical research involving ca 759 ;. Pure and Applied Chemistry, 66(つ): 1017-1024.

Byers, T. and Perry, G. (1992). Dietary carotenes, vitamin $\mathrm{C}$, and vitamin $\mathrm{E}$ as protective antioxidants in human cancers. Annual Review of Nutrition, 12(1): 139-159.

Cruess, W. V. (1997). Commercial Fruit and Vegetable Products; A Textbook for student, investigator and manufacturer (No. 664.8 C955). McGraw-Hill book company, Inc.

CSIR (2010). Council of Scientific and Industrial Research (1948-1976). The wealth of India, New Delhi.

Czepa, A. and Hofmann, T. (2003). Structural and sensory characterization of compounds contributing to the bitter off-taste of carrots (Daucus carota L.) and carrot puree. Journal of Agricultural and Food Chemistry, 51(13): 3865-3873.

Davidson-Hunt, I. (2006). Ecological ethnobotany: stumbling toward new practices and paradigms. MASA Journal, 16: 1-13.

Durrani, A.M.; Srivastava, P.K. and Verma, S. (2011). Development and quality evaluation of honey based carrot candy. Journal of Food Science and Technology, 48(4): 502-505.

Edwards, C.G. and Lee, C.Y. (1986). Measurement of provitamin A carotenoids in fresh and canned carrots and green peas. Journal of Food Science, 51(2): 534-535.

El-Houri, R.B., Kotowska, D., Christensen, K.B., Bhattacharya, S., Oksbjerg, N., Wolber, G., Kristiansen, K. and Christensen, L.P. (2015). Polyacetylenes from carrots (Daucus carota) improve glucose uptake in vitro in adipocytes and myotubes. Food Function, 6(7): 2135-2144.

El-Moghazi， A.M. (1980). Flavonoids of Daucus carota. Planta Medica, 40: 382-385.
Fu, H.W.; Zhang, L.; Yi, T. and Tian, J.K. (2009). A new sesquiterpene from the fruits of Daucus carota L. Molecules, 14(8): 2862-2867.

Gilani, A.; Shaheen, F. and Saeed, S.A. (1994). Cardiovascular action of Daucus carota. Archives of Pharmacal Research, 17(3): 150-153.

Gill, H.S. and Kataria, A.S. (1974). Some biochemical studies in European and Asiatic varieties of carrot (Daucus carota). Current science, 32-36.

Gopalan, C.R.B.V., Sastri, B.R. and Balasubramanian, S.C. (1991). Nutritive value of Indian foods. National Institute of Nutrition, Indian Council of Medical Research, $47 \mathrm{p}$.

Grassmann, J., Schnitzler, W. H. and Habegger, R. (2007). Evaluation of different coloured carrot cultivars on antioxidative capacity based on their carotenoid and phenolic contents. International Journal of Food Sciences and Nutrition, 58(8): 603-611.

Gupta, M., Bajwa, U. and Sandhu, K.S. (2005). Optimization of variables associated with the processing of carrot-milk cake. Journal of Food Science and Technology, 42(1): 16-22.

Hedren, E., Diaz, V. and Svanberg, U. (2002). Estimation of carotenoid accessibility from carrots determined by an in vitro digestion method. European Journal of Clinical Nutrition, 56(5): 425-428.

Heinonen, M. I. (1990). Carotenoids and provitaminA activity of carrot (Daucus carota L.) cultivars. Journal of Agricultural and Food Chemistry, 38(3): 609-612.

Jayaraman, K.S. and Gupta, D.D. (1978). Development and storage stability of intermediate moisture carrot. Journal of Food Science, 43(6): 1880-1881.

Kahkonen, M.P., Hopia, A.I., Vuorela, H.J., Rauha, J.P., Pihlaja, K., Kujala, T.S. and Heinonen, M. (1999). Antioxidant activity of plant extracts containing phenolic compounds. Journal of Agricultural and Food Chemistry, 47(10): 3954-3962.

Kalra, C.L.; Kulkarni, S.G. and Berry, S.K. (1987). The carrot (Daucus carota L.) - 
A most popular root vegetable. Indian Food Packer, 41(6): 46-73.

Karakaya, S.N.E.1. and Tas, A.A.S. (2001). Antioxidant activity of some foods containing phenolic compounds. International Journal of Food Sciences and Nutrition, 52(6): 501-508.

Karangwa, E., Khizar, H., Rao, L., Nshimiyimana, D.S., Foh, M.B.K., Li, L. and Zhang, X. M. (2010). Optimization of processing parameters for clarification of blended carrotorange juice and improvement of its carotene content. Advance Journal of Food Science and Technology, 2(5): 268-278.

Khalil, N., Ashour, M., Singab, A.N. and Salama, O. (2015). Chemical composition and biological activity of the essential oils obtained from yellow and red Carrot fruits cultivated in Egypt. IOSR Journal of Pharmacy and Biological Sciences, 10(2): 13-19.

Kirca, A., Ozkan, M. and Cemeroglu, B. (2007). Storage stability of strawberry jam color enhanced with black carrot juice concentrate. Journal of Food Processing and Preservation, 31(5): 531-545.

Krinsky, N.I. (1989). Antioxidant functions of carotenoids. Free Radical Biology and Medicine, 7(6): 617-635.

Ksouri, A., Dob, T., Belkebir, A., Krimat, S. and Chelghoum, C. (2015). Chemical composition and antioxidant activity of the essential oil and the methanol extract of Algerian wild carrot (Daucus carota L. spp carota (L.). Thell. Journal of Materials and Environmental Sciences, 6(3): 784-791.

Leja, M., Kaminska, I., Kramer, M., Maksylewicz-Kaul, A., Kammerer, D., Carle, R. and Baranski, R. (2013). The content of phenolic compounds and radical scavenging activity varies with carrot origin and root color. Plant Foods for Human Nutrition, 68(2): 163170.

Madan, S. and Dhawan, S.S. (2005). Development of value added product 'Candy' from carrots. Process Food Industry, 8(3): 26-29.
Manjunatha, S.S., Mohan Kumar, B.L. and Das Gupta, D.K. (2003). Development and evaluation of carrot kheer mix. Journal of Food Science and Technology, 40(3): 310-312.

Mayer-Miebach, E. and Spie, W.E.L. (2003). Influence of cold storage and blanching on the carotenoid content of Kintoki carrots. Journal of Food Engineering, 56(2-3): 211-213.

Mittal, P.R., Laxman, P.J. and Ramesshvar, P.K. (2011). Protective effect of Daucus carota root extract against ischemia reperfusion injury in rats. Pharmacology, 1: 432-439.

Muralidharan, P., Balamurugan, G. and Kumar, P. (2008). Inotropic and Cardioprotective Effects of Daucus carota Linn. on isoproterenol-induced myocardial infarction. Bangladesh Journal of Pharmacology, 3: 74- 79.

Negi, P. S. and Roy, S. K. (2001). The effect of blanching on quality attributes of dehydrated carrots during long-term storage. European Food Research and Technology, 212(4): 445-448.

Panalaks, T. and Murray, T. K. (1970). The effect of processing on the content of carotene isomers in vegetables and peaches. Canadian Institute of Food Technology Journal, 3(4): 145-151.

Patil, M.V.K., Kandhare, A.D. and Bhise, S.D. (2012). Pharmacological evaluation of ethanolic extract of Daucus carota Linn root formulated cream on wound healing using excision and incision wound model. Asian Pacific Journal of Tropical Biomedicine, 2(2): S646-S655.

Poudyal, H., Panchal, S. and Brown, L. (2010). Comparison of purple carrot Juice and $\beta$-carotene in a highcarbohydrate, high-fat diet-fed rat model of the metabolic syndrome. British Journal of Nutrition, 104: 13221332.

Rokheri, N., Mrabet, Y., Dziri, S., Chaabane, H., Jemli, M., Fernandez, X. and Boulila, A. (2013). Variation of the chemical composition and antimicrobial activity of the essential oils of natural populations of Tunisian Daucus carota L. (Apiaceae). 
Chemistry and Biodiversity, 10(12): 2278-2290.

Roy, M.C., Alam, M., Saeid, A., Das, B.C., Mia, Md. B., Rahman, Md.A., Eun, J.B. and Ahmed, M. (2017). Extraction and characterization of pectin from pomelo peel and its impact on nutritional properties of carrot jam during storage. Journal of Food Processing and Preservation, 42(1): e13411.

Rubatzky, V.E., Quiros, C.F. and Simon, P.W. (1999). Carrots and related vegetable Umbelliferae. CABI publishing.

Sampathu, S.R., Chakraberty, S., Kamal, P., Bisht, H.C., Agrawal, N.D. and Saha, N.K. (1981). Standardization and preservation of carrot halwa - an Indian sweet. Indian Food Packer, 35(6): 6067.

Shakuntalamanay, N. and Shadaksharaswamy, M. (1997). FoodsFacts and Principles. New Age International (P) Ltd, Publishers, New Delhi, pp. 206-207.

Sharma, H.K., Kaur, J., Sarkar, B.C., Singh, C. and Singh, B. (2009). Effect of pretreatment conditions on physicochemical parameters of carrot juice. International Journal of Food Science and Technology, 44(1): 1-9.

Shukla, N., Sridevi, G. and Gopkumar, P. (2014). Pharmacological and histochemical screening for Hair growth promoting activity of Daucus carota herbal gel. RRJPPS, 3(4): 1-5.

Simon, P.W. and Wolff, X.Y. (1987). Carotenes in typical and dark orange carrots. Journal of Agricultural and Food Chemistry, 35(6): 1017-1022.

Simon, P.W. and Lindsay, R.C. (1983). Effects of processing upon objective and sensory variables of carrots (Flavour, vitamin content, and texture, food quality). Journal of American Society for Horticultural Science, 5(3): 115-129.

Sinchaipanit, P. and Kerr, W.L. (2007). Effect of reducing pulp-particles on the physical properties of carrot juice. Asian Food Journal, 3: 205-214.
Singh, H. (2001). Osmotic dehydration of carrot shreds for Gazrella preparation. Journal of Food Science and Technology, 38(2): 152-154.

Singh, P. and Kulshrestha, K. (2008). Nutritional quality of food supplements based on carrot powder and grits. Journal of Food Science and Technology, 45(1): 99-101.

Singh, S., Shivhare, U.S., Ahmed, J. and Raghavan, G.S.V. (1999). Osmotic concentration kinetics and quality of carrot preserve. Food Research International, 32(7): 509-514.

Sivanantham, S. and Thangaraj, N. (2015). Phytochemical screening, characterization, compound identification and separation from Daucus carota L. International Journal Current Research Bioscience and Plant Biology, 2(7): 168-172.

Suman, M. and Krishna Kumari, K. (2002). A study on sensory evaluation, $\beta$-carotene retention and shelf-life of dehydrated carrot products. Journal of Food Science and Technology, 39(6): 677681.

Sun, T., Simon, P.W. and Tanumihardjo, S.A. (2009). Antioxidant phytochemicals and antioxidant capacity of biofortified carrots (Daucus carota L.) of various colours. Journal of Agriculture and Food Chemistry, 57(10): 4142- 4147.

Vasudevan, M. and Parle, M. (2006). Pharmacological evidence for the potential of Daucus carota in the management of cognitive dysfunctions. Biological and Pharmaceutical Bulletin, 29(6): 1154-1161.

Verma, R.S., Padalia, R.C. and Chauhan, A. (2014). Chemical composition variability of essential oil during ontogenesis of Daucus carota L. subsp. sativus (Hoffm.) Arcang. Industrial Crops and Products, 52: 809-814.

Zhang, D. and Hamauzu, Y. (2005). Phenolic compounds and their antioxidant properties in different tissues of carrots (Daucus carota L.). Journal of Food Agriculture and Environment, 2: 95100.

$\begin{array}{ll}\text { Received } & \text { : January, 2019 } \\ \text { Revised } & \text { : March, 2019 } \\ \text { Published } & : \text { June, 2019 }\end{array}$

